\title{
Erratum to "Streamlined Approach for Infrapubic Placement of an Inflatable Penile Prosthesis"
}

\author{
Edward Karpman \\ El Camino Urology Medical Group, Mountain View, CA 94040, USA \\ Correspondence should be addressed to Edward Karpman, edwardkarpman@yahoo.com \\ Received 9 August 2012; Accepted 21 August 2012 \\ Copyright ( 2012 Edward Karpman. This is an open access article distributed under the Creative Commons Attribution License, \\ which permits unrestricted use, distribution, and reproduction in any medium, provided the original work is properly cited.
}

With reference to the paper "Streamlined Approach for Infrapubic Placement of an Inflatable Penile Prosthesis", we want to change in the introduction section paragraph 3 on page 1 to read "our streamlined approach for infrapubic placement of penile prosthesis is a variation of the minimally invasive approach originally published by Perito $[1,2]$.”

\section{References}

[1] P. E. Perito, "Minimally invasive infrapubic inflatable penile implant," The Journal of Sexual Medicine, vol. 5, no. 1, pp. 2730, 2008.

[2] P. E. Perito, "Ectopic reservoir placement-no longer in the space of Retzius," The Journal of Sexual Medicine, vol. 8, no. 9, pp. 2395-2398, 2011. 


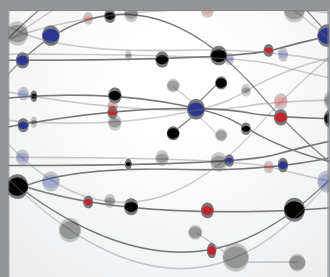

The Scientific World Journal
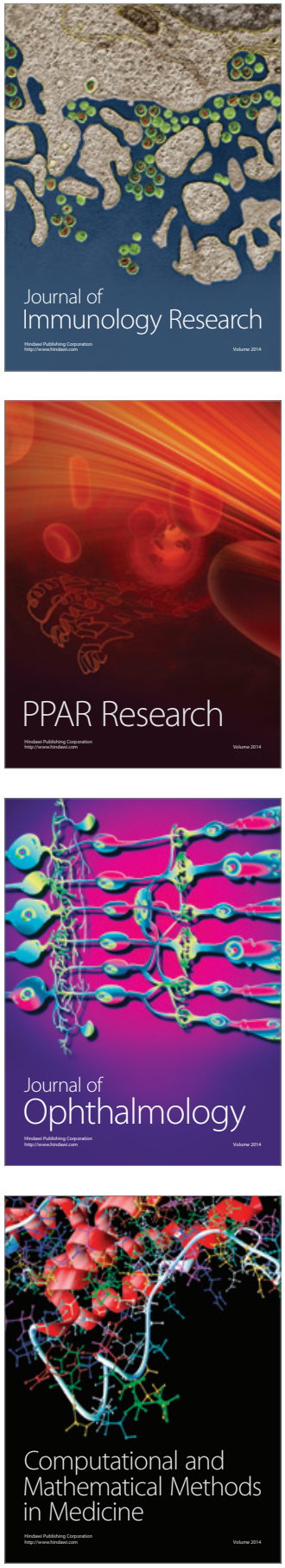

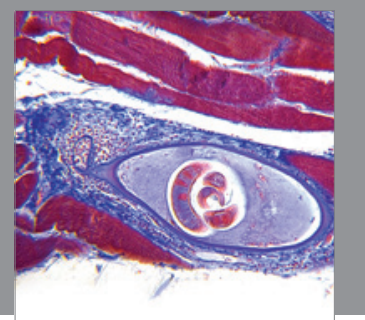

Gastroenterology

Research and Practice
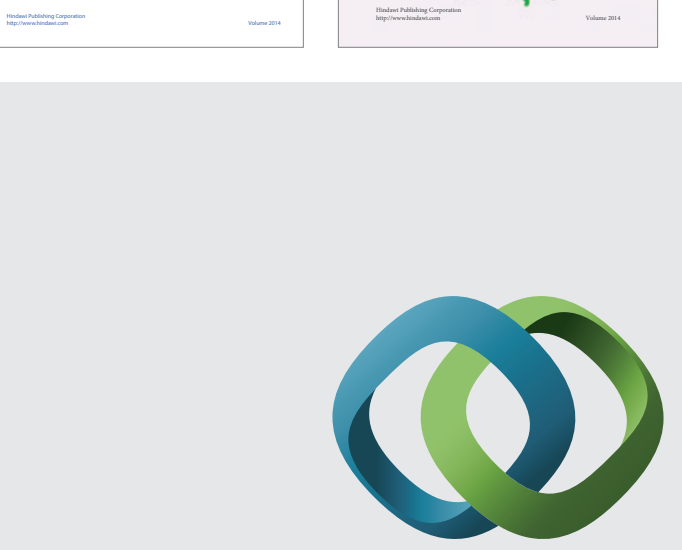

\section{Hindawi}

Submit your manuscripts at

http://www.hindawi.com
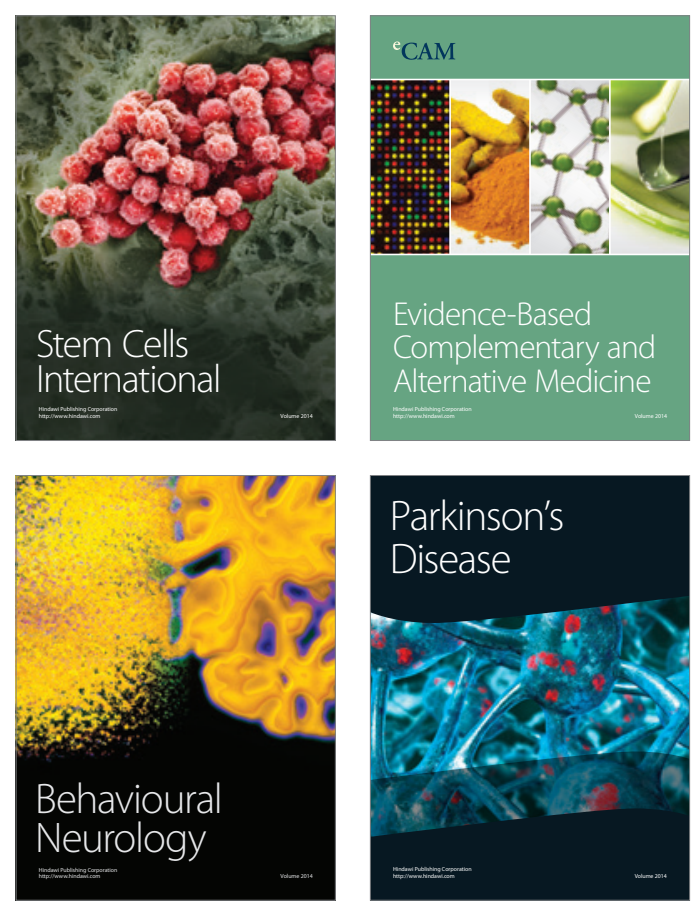

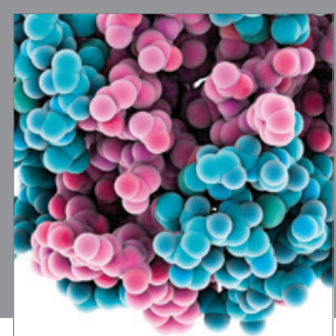

Journal of
Diabetes Research

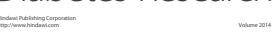

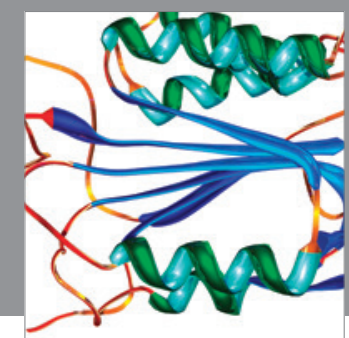

Disease Markers
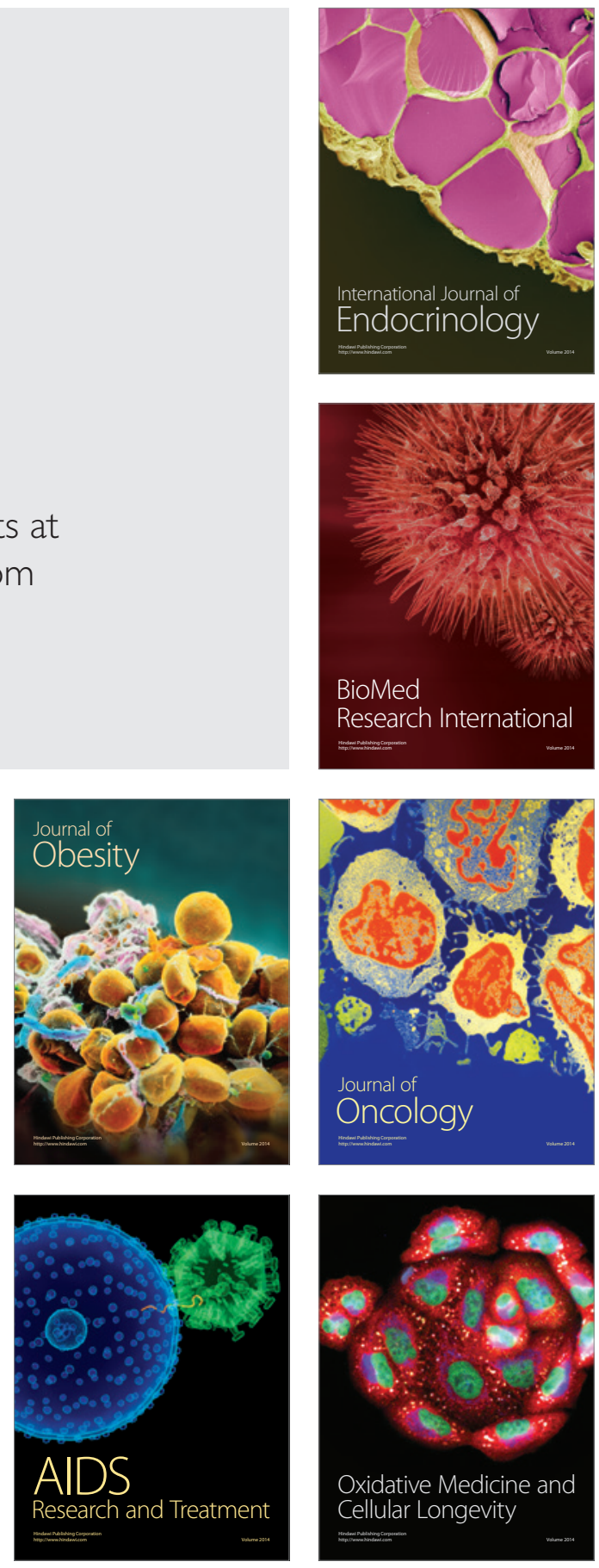